\title{
Preferred Orientation of TiN Coatings Enables Stable Zinc Anodes
}

Jiaxian Zheng, ${ }^{1+}$ Zhen Cao, ${ }^{5 \dagger}$ Fangwang Ming, ${ }^{2}$ Hanfeng Liang, ${ }^{1 *}$ Zhengbing Qi, ${ }^{4}$ Wanqiang Liu, ${ }^{3 *}$ Chuan Xia, ${ }^{6,7}$ Cuixue Chen, ${ }^{1}$ Luigi Cavallo, ${ }^{5}$ Zhoucheng Wang, ${ }^{1,{ }^{*}}$ Husam N. Alshareef ${ }^{*}$

'State Key Laboratory of Physical Chemistry of Solid Surfaces, College of Chemistry and Chemical Engineering, Xiamen University, Xiamen 361005, China

${ }^{2}$ Materials Science and Engineering, King Abdullah University of Science and

Technology (KAUST), Thuwal 23955, Saudi Arabia

${ }^{3}$ School of Materials Science and Engineering, Changchun University of Science and Technology, Changchun 130022, China

${ }^{4}$ Key Laboratory of Functional Materials and Applications of Fujian Province, School of Materials Science and Engineering, Xiamen University of Technology, Xiamen 361024, China

${ }^{5}$ KAUST Catalysis Center (KCC), King Abdullah University of Science and Technology, Thuwal 23955, Saudi Arabia

${ }^{6}$ Yangtze Delta Region Institute (Huzhou), University of Electronic Science and Technology of China, Huzhou 313001, Zhejiang, China

${ }^{7}$ School of Materials and Energy, University of Electronic Science and Technology of China, Chengdu 611731, China

*Email: hfliang@xmu.edu.cn (H. Liang); wqliu1979@126.com (W. Liu); zcwang@xmu.edu.cn (Z. Wang); husam.alshareef@kaust.edu.sa (H. N. Alshareef)

$\dagger$ These authors contributed equally. 


\section{Experimental Section}

Preparation of TiN coated $\mathrm{Zn}$ anodes. TiN thin films were deposited onto pure $\mathrm{Zn}$ foil $(0.2 \mathrm{~mm})$ by reactive DC magnetron sputtering using Ti target under a mixed gas flow of Ar and $\mathrm{N}_{2}(99.995 \%$ purity with a total flux of $60 \mathrm{sccm})$. Prior to the deposition, the $\mathrm{Zn}$ foil was polished by sandpaper and then ultrasonically cleaned with acetone and alcohol successively for $15 \mathrm{~min}$. The distance between the Ti target and $\mathrm{Zn}$ substrate was $100 \mathrm{~mm}$. The base pressure of vacuum chamber was below $6 \times 10^{-4} \mathrm{~Pa}$ and the deposition time was $60 \mathrm{~min}$. During the deposition, a DC power (MDX 1K, Advanced Energy) of $250 \mathrm{~W}$ was applied to the substrate and the deposition temperature was $120^{\circ} \mathrm{C}$. The substrate was biased at $0 \mathrm{~V}$. The $\mathrm{N}_{2}$ gas ratio was set at $2.6 \%$ and $15 \%$ to induce the preferential growth of TiN (111) and TiN (200) films, respectively.

Preparation of $\mathrm{MnO}_{2}$ cathode. The $\mathrm{MnO}_{2}$ nanorods were synthesized using a hydrothermal method. ${ }^{1} 15 \mathrm{~mL}$ of $\mathrm{MnSO}_{4} \cdot \mathrm{H}_{2} \mathrm{O}(380 \mathrm{mg})$ solution and $15 \mathrm{ml} \mathrm{KMnO} 4(237 \mathrm{mg})$ solution were mixed under stirring. The mixture was then heated $160{ }^{\circ} \mathrm{C}$ for $12 \mathrm{~h}$ in a Teflonlined autoclave. After the reaction, the precipitation was collected and washed with deionized water, and then dried at $80{ }^{\circ} \mathrm{C}$ overnight. For the electrode preparation, the $\mathrm{MnO}_{2}$ nanorods were mixed with polyvinylidene fluoride (PVDF) and active carbon in N-methyl pyrrolidine (NMP) in a weight ratio of 7:1:2 and then casted onto a piece of stainless-steel foil. The mass loading of active material was $\sim 2 \mathrm{mg} \mathrm{cm}^{-2}$.

Characterizations. The microstructures of TiN films were investigated by scanning electron microscopy (SEM, ZEISS Sigma) and transmission electron microscopy (TEM, FEI Tecnai-F20). X-ray diffraction (XRD) was performed using a Philips X'pert PRO diffractor with $\mathrm{Cu} \mathrm{K \alpha}$ radiation. Raman spectra were acquired on an Xplora Raman microscope using an excitation wavelength of $785 \mathrm{~nm}$. X-ray photoelectron spectroscopy (XPS, PHI-Quantum 2000) measurement was carried out to probe the surface chemical states and composition.

Electrochemical measurements. $\mathrm{Zn} \mid \mathrm{Zn}$ symmetric cells were assembled using coin cells (CR2032) with a glass fiber as the separator and an aqueous solution $(150 \mu \mathrm{L})$ containing 2.0 $\mathrm{M} \mathrm{ZnSO}_{4}$ as the electrolyte. The $\mathrm{Zn} \mid \mathrm{MnO}_{2}$ full cells were assembled in the same way except that a solution of $2.0 \mathrm{M} \mathrm{ZnSO}_{4}$ and $0.1 \mathrm{M} \mathrm{MnSO}_{4}$ was used as the electrolyte. The battery performance was tested using a Neware battery testing system. The cyclic voltammetry (CV) measurement was conducted on a CHI660E electrochemical workstation in the voltage range of $0.9-1.8 \mathrm{~V}$. The electrochemical impedance spectroscopy (EIS) tests were performed over the frequency range from $10 \mathrm{mHz}$ to $100 \mathrm{kHz}$ at the open circuit potential. 
Simulations. The relative stability of different ways of zinc hydroxide sulfate (ZHS, here considered as a layered $\mathrm{Zn}(\mathrm{OH})_{2}$ with $\mathrm{SO}_{4}{ }^{2-}$ anions located within the two $\mathrm{Zn}(\mathrm{OH})$ layers for structural modelling) aggregation onto the TiN substrates were evaluated based on a prototypical model using the density functional theory (DFT) calculations. We have built two different TiN surfaces, namely, the (111) facet and the (200) facet based on the experimental characterizations. Both of the models contain 6 layers of the TiN materials. Thereafter, we constructed one layer of $\mathrm{Zn}(\mathrm{OH})$ onto the TiN surface forming a ring-like structure, and the $\mathrm{Zn}(\mathrm{OH})$ above other $\mathrm{Zn}(\mathrm{OH})$ to mimic the situation that $\mathrm{Zn}(\mathrm{OH})$ can grow along the direction perpendicular to the TiN surface. The relative stability of these two situations were evaluated by comparing the energy differences of these two structures. The calculations were performed at the Perdew-Burke-Ernzerhof $(\mathrm{PBE})^{2}$ level of DFT calculations and the electrons were constrained by the $\mathrm{U}$ corrections ${ }^{3,4}$ because the pure DFT functional can overestimate the delocalization of the electrons. The PAW method was employed to describe the electrons with a $450 \mathrm{eV}$ energy cutoff. The Brillouin zone was described using the $3 * 3 \mathrm{k}$-point mesh around the gamma point. The structural optimization was considered as converged if the HellmannFeynman force is smaller than $0.001 \mathrm{eV} / \AA$. 


\section{Characterization of the TiN coatings}
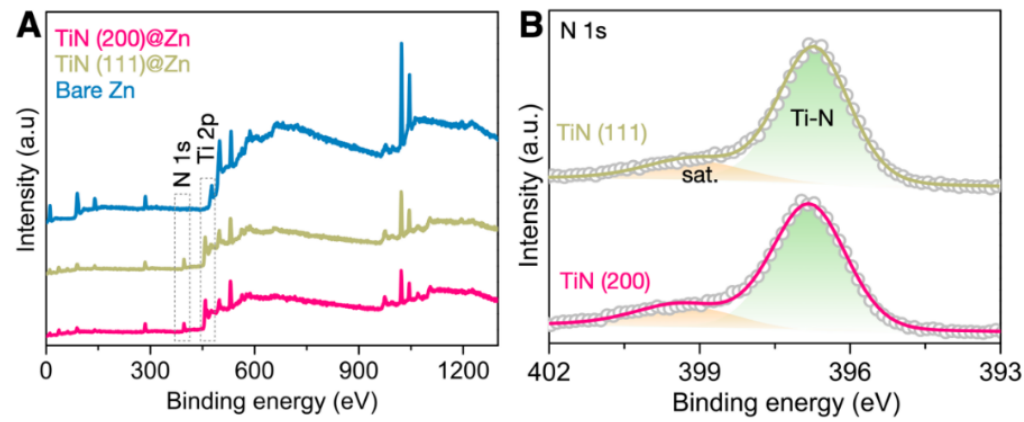

Figure S1. (A) XPS survey spectra of bare Zn and TiN coated Zn anodes. (B) N 1s spectra of TiN (111) and (200) coatings on Zn foil.

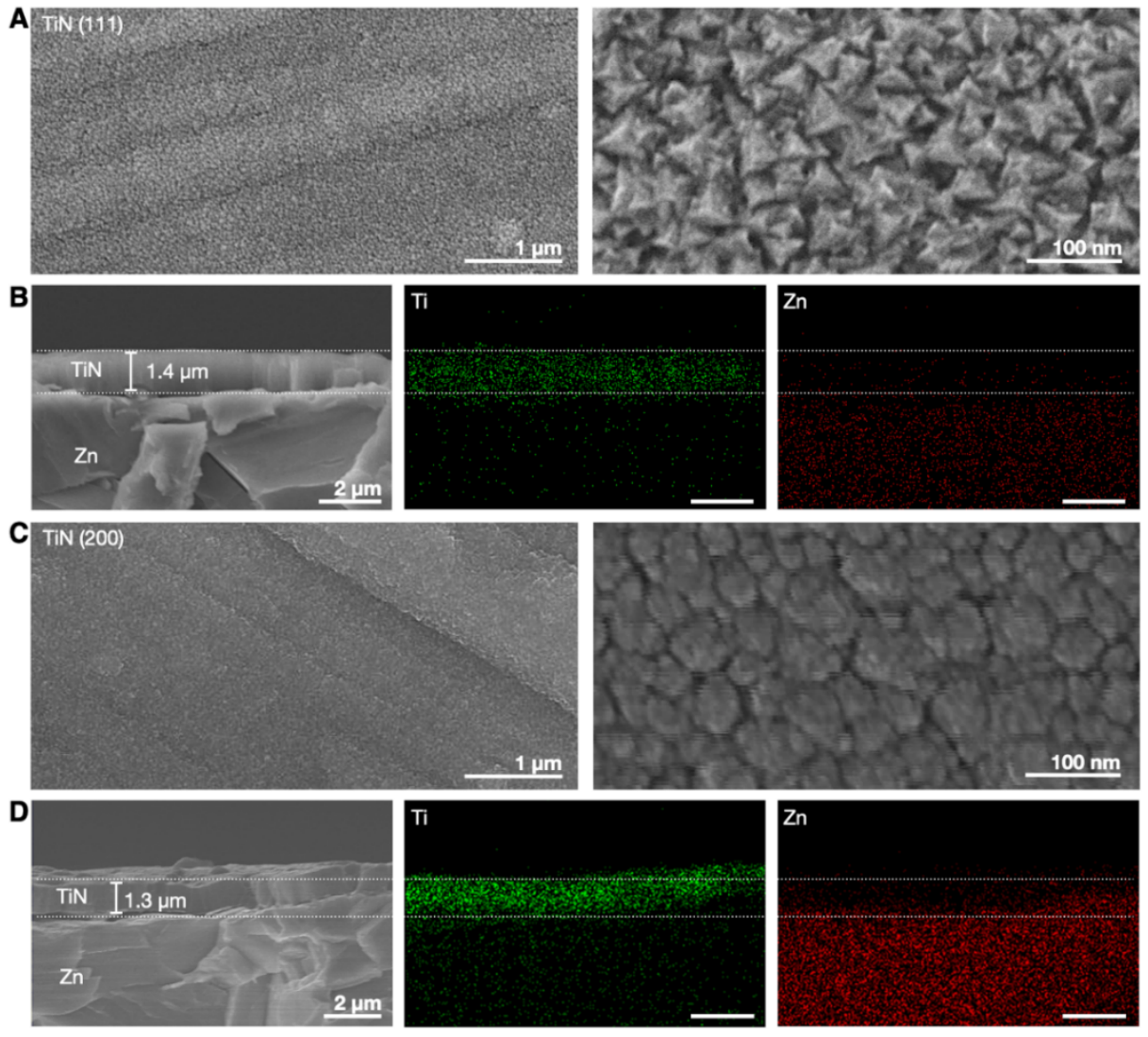

Figure S2. SEM images and elemental maps of (A and B) TiN (111)@Zn and (C and D) Ti (200)@Zn anodes. 


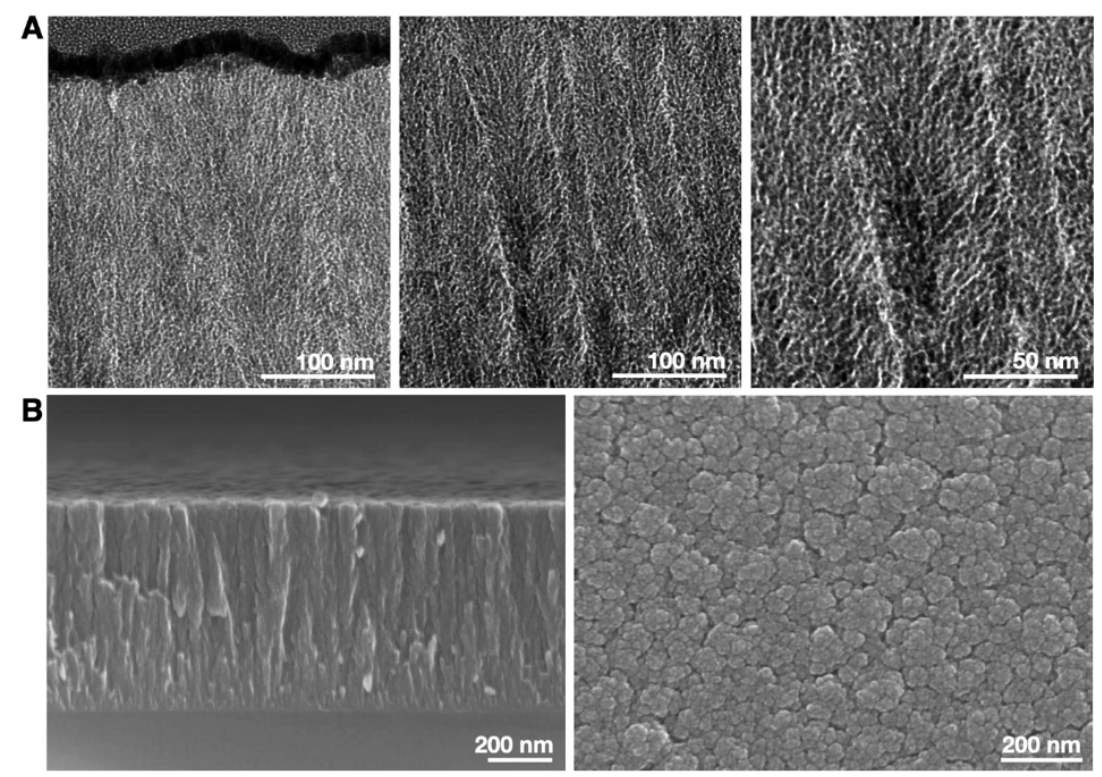

Figure S3. (A) TEM images of TiN (200) coatings on Zn foil. (B) SEM images of the TiN (200) coatings deposited on Si substrate. The columnar structure can be clearly seen from these images.
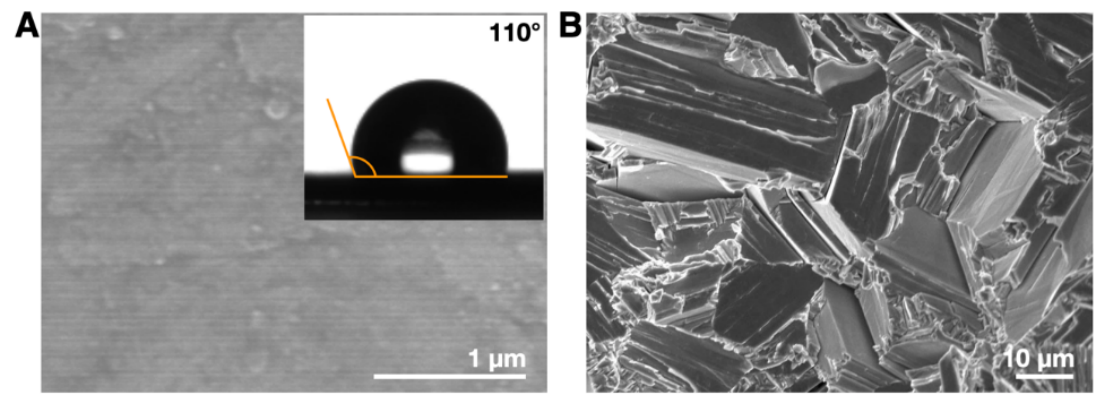

Figure S4. (A) SEM image showing the surface morphology of bare $\mathrm{Zn}$ foil. The inset shows the water contact angle. (B) SEM image of the cross section of the bare $\mathrm{Zn}$ foil. 


\section{Electrochemical performance of the various $\mathrm{Zn}$ anodes}

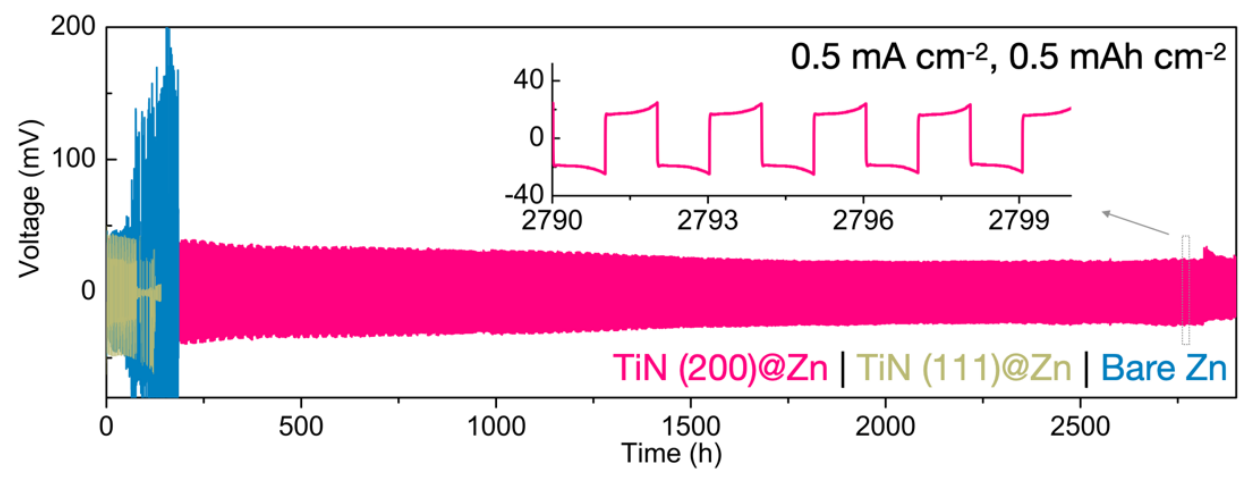

Figure S5. Galvanostatic cycling of symmetric cells at $0.5 \mathrm{~mA} \mathrm{~cm}{ }^{-2}$ and $0.5 \mathrm{mAh} \mathrm{cm}^{-2}$,
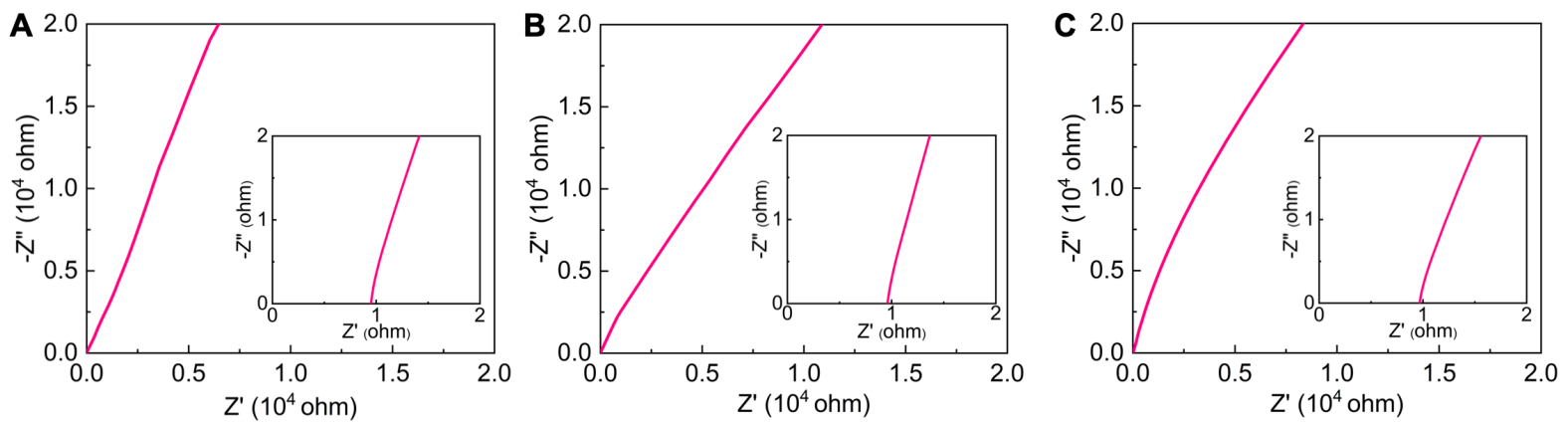

Figure S6. The EIS spectra of (a) Ti|Ti, (b) TiN (200)@Ti|TiN (200)@Ti, and (c) TiN (111)@Ti|TiN(111)@Ti.

The EIS spectra were collected to evaluate the $\mathrm{Zn}^{2+}$ ionic conductivity of TiN (200) and TiN (111) coatings according to the following equation:

$$
\sigma=\frac{L}{R_{b} \cdot S}
$$

which $R_{\mathrm{b}}$ represents the resistance according to the EIS measurement, $S$ is the effective area of sample $\left(1.32 \mathrm{~cm}^{2}\right)$, and $L$ is the thickness of TiN (200) and TiN (111) coatings (1.3 and 1.4 $\mu \mathrm{m}$, respectively). The resistance of $\mathrm{TiN}$ (200) and TiN (111) coatings can be obtained from the Nyquist plots. The total resistance of Ti|Ti, TiN (200)@Ti|TiN (200)@Ti and TiN (111)@Ti|TiN (111)@Ti are 0.89,0.961 and $0.968 \Omega$, respectively. $R_{\mathrm{b}}(\mathrm{TiN})=R($ total $)-R$ (glass fiber). The calculated ionic conductivity $(\sigma)$ values of TiN (200) and TiN (111) coatings are $1.39 \times 10^{-3}$ and $1.36 \times 10^{-3} \mathrm{~S} \mathrm{~cm}^{-1}$, respectively. 

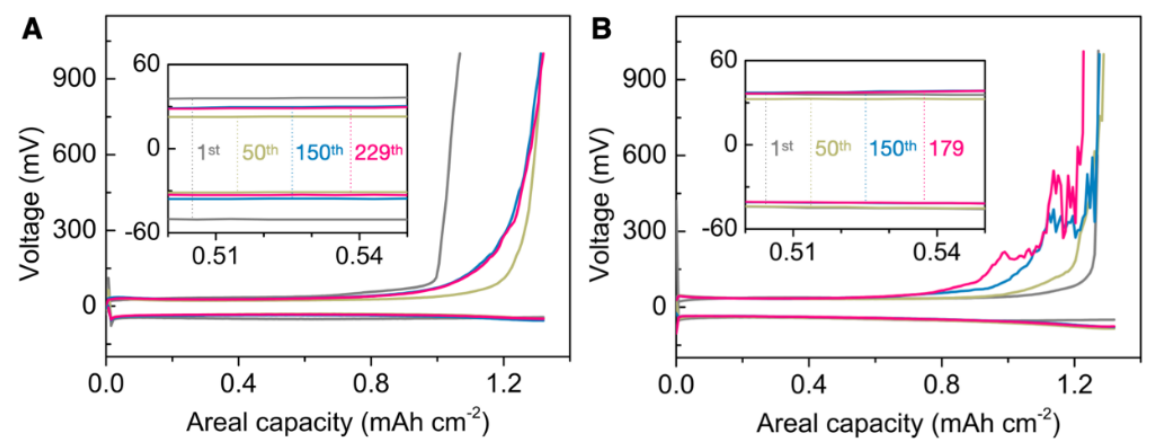

Figure S7. Voltage-capacity profiles of (A) TiN (200)@Zn and (B) bare Zn based symmetric cells. The insets show the voltage hysteresis at different cycles.

\section{Morphological and structural evolution of various $\mathrm{Zn}$ anodes after cycling}
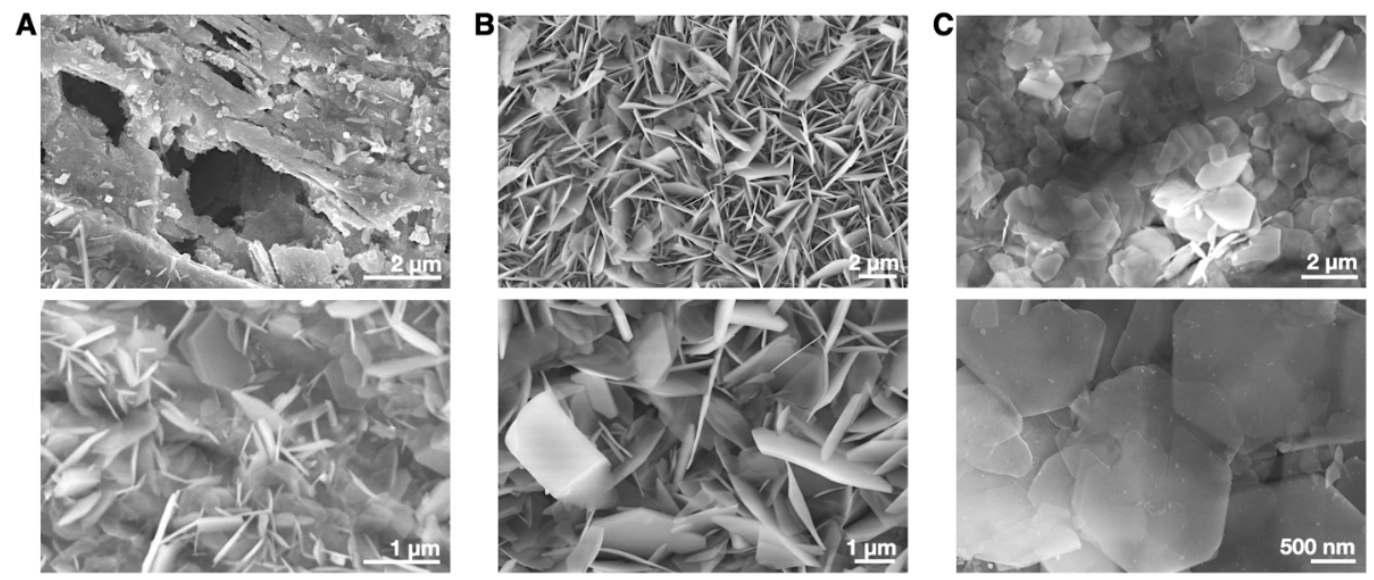

Figure S8. SEM images showing the surface morphologies of (A) bare $\mathrm{Zn}$, (B) TiN (111)@Zn, and (C)TiN(200)@Zn anodes after 4 h cycling at 0.5 mA cm${ }^{-2}$. 


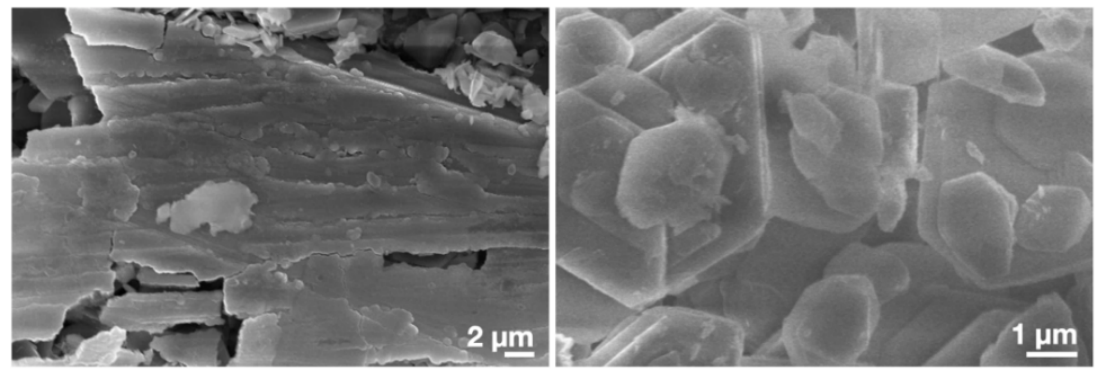

Figure S9. SEM images showing the surface morphology of TiN (200)@Zn anodes after $1000 \mathrm{~h}$ cycling at $0.5 \mathrm{~mA} \mathrm{~cm}^{-2}$.
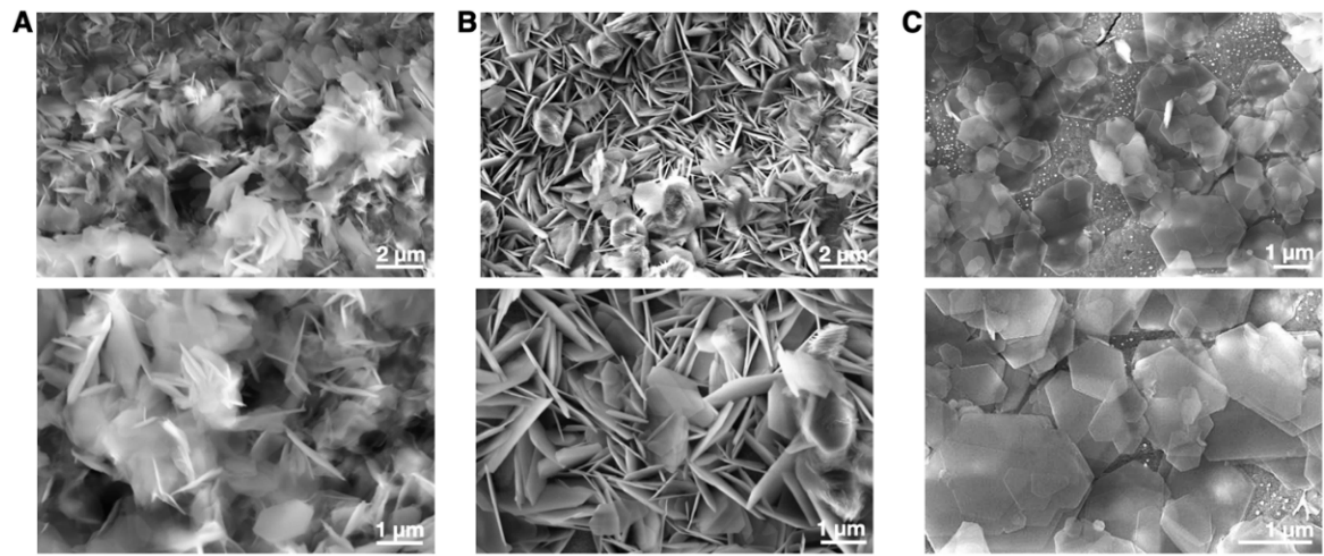

Figure S10. SEM images showing the surface morphologies of (A) bare Zn, (B) TiN (111)@Zn, and (C) TiN (200)@Zn anodes after 4 h cycling at 2 mA cm-2.
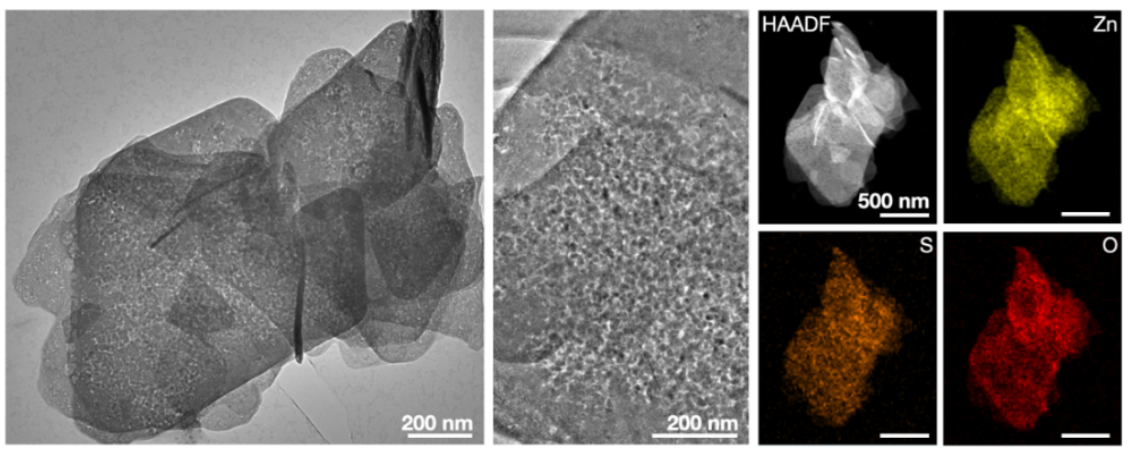

Figure S11. TEM images and elemental maps of the nanosheets formed at TiN (200)@Zn surface after $4 \mathrm{~h}$ cycling. 


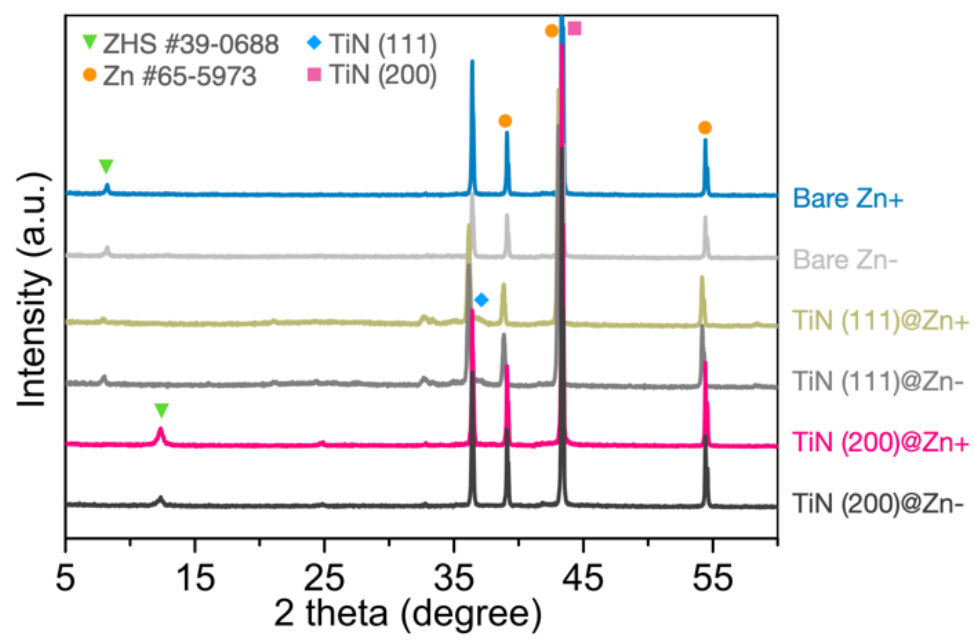

Figure S12. XRD patterns collected from both the cathode and anode sides of the three symmetric cells.
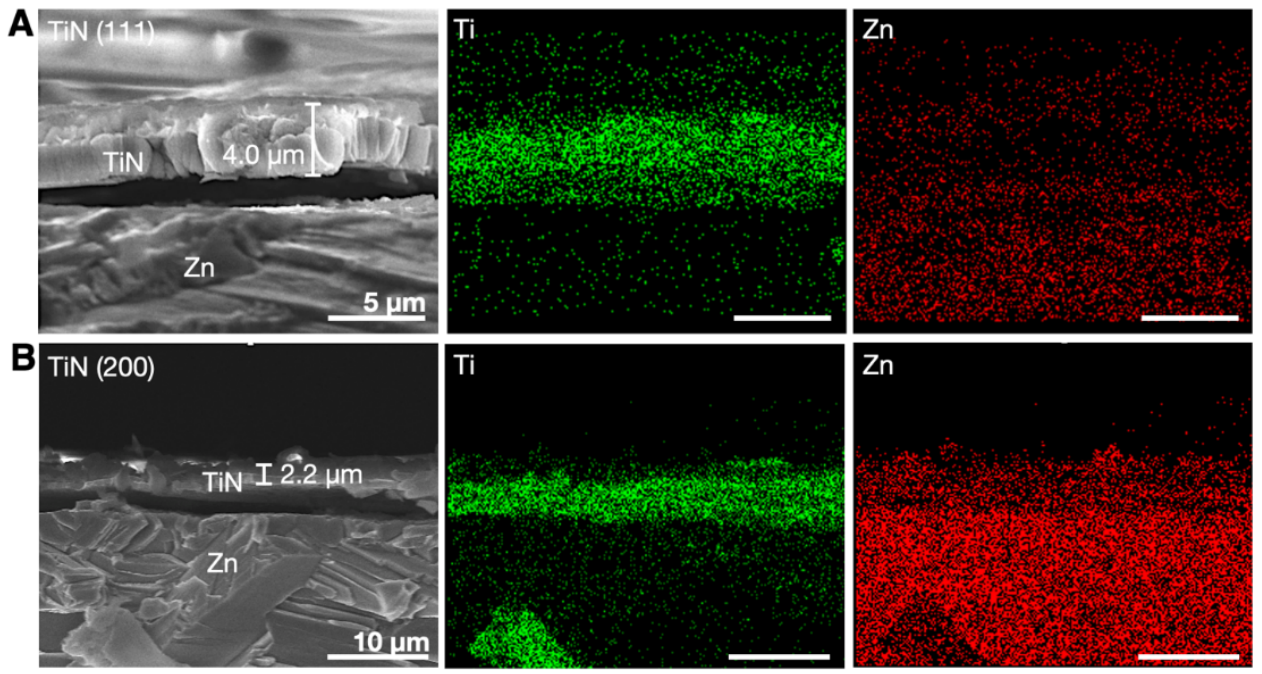

Figure S13. Cross-section SEM images and elemental maps of (A) TiN (111)@Zn and (B) TiN(200)@Zn anodes after $4 \mathrm{~h}$ cycling at $0.5 \mathrm{~mA} \mathrm{~cm} \mathrm{c}^{-2}$ and $0.5 \mathrm{mAh} \mathrm{cm}$. 

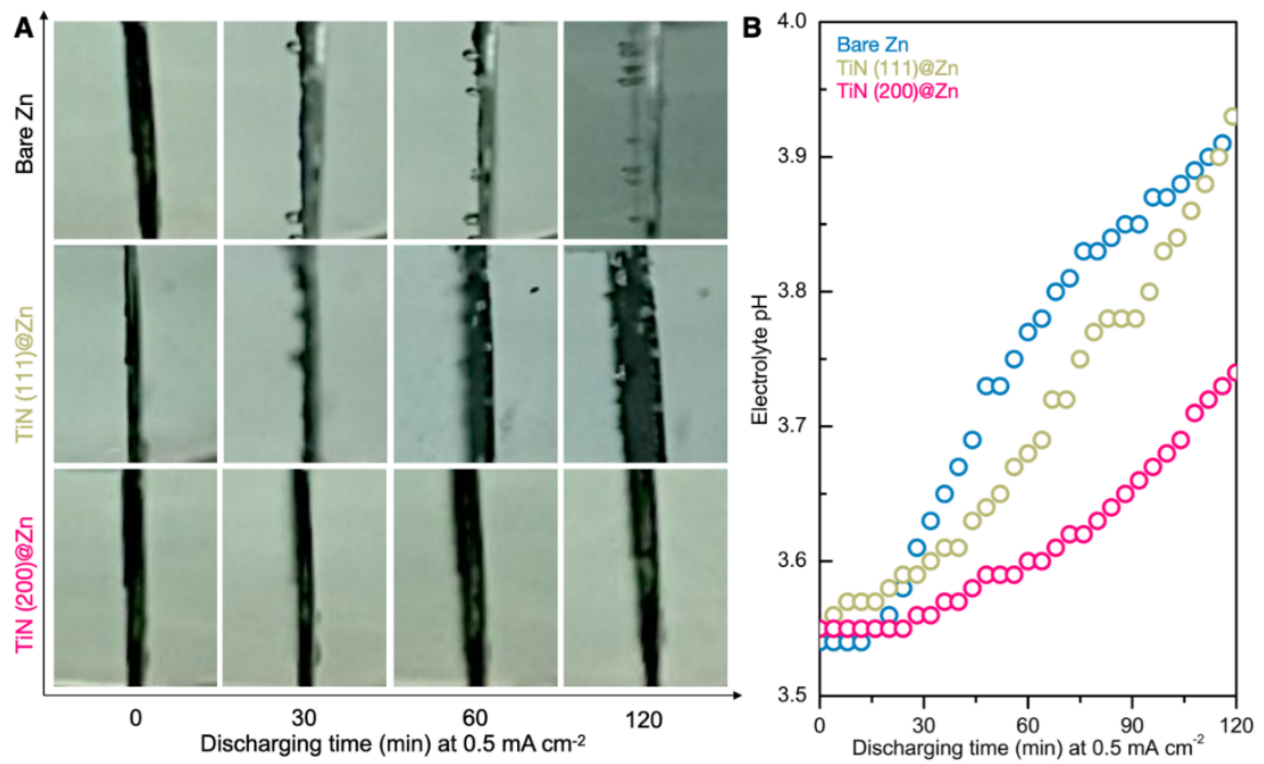

Figure S14. (A) The optical images showing the gas evolution of $\mathrm{Zn}$ electrodes upon discharging at $0.5 \mathrm{~mA} \mathrm{~cm}^{-2}$. (B) The changes in electrolyte $\mathrm{pH}$ against discharging time at a current density of $0.5 \mathrm{~mA} \mathrm{~cm}^{-2}$.
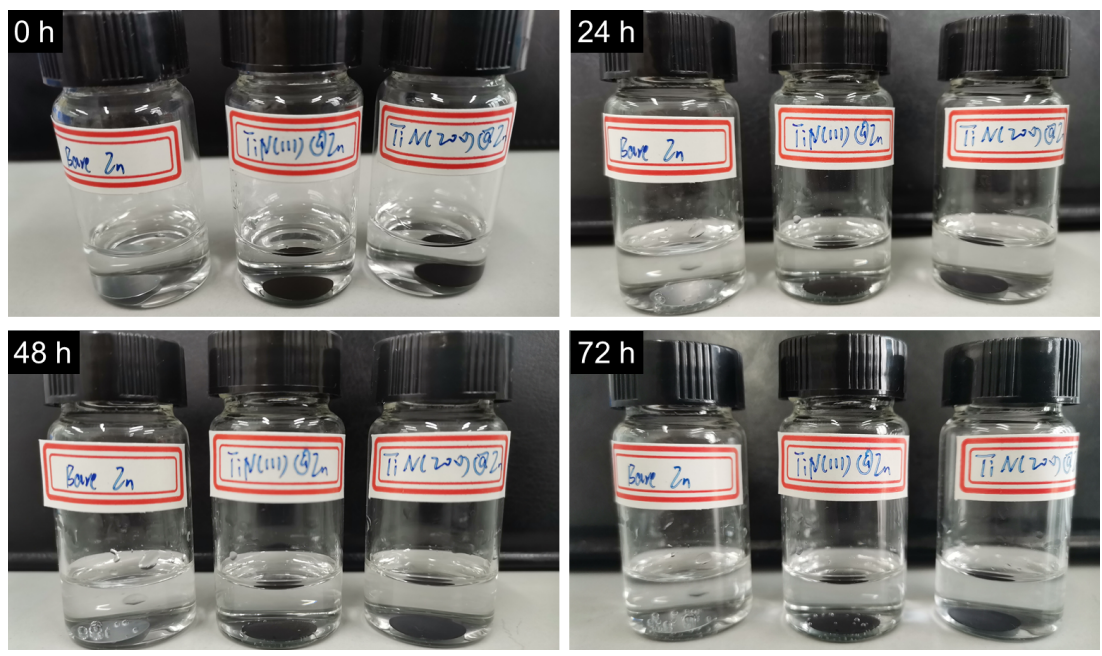

Figure S15. Optical images showing the gas evolution of the three $\mathrm{Zn}$ anodes during resting mode by soaking the $\mathrm{Zn}$ electrodes in the electrolyte for 3 days. 


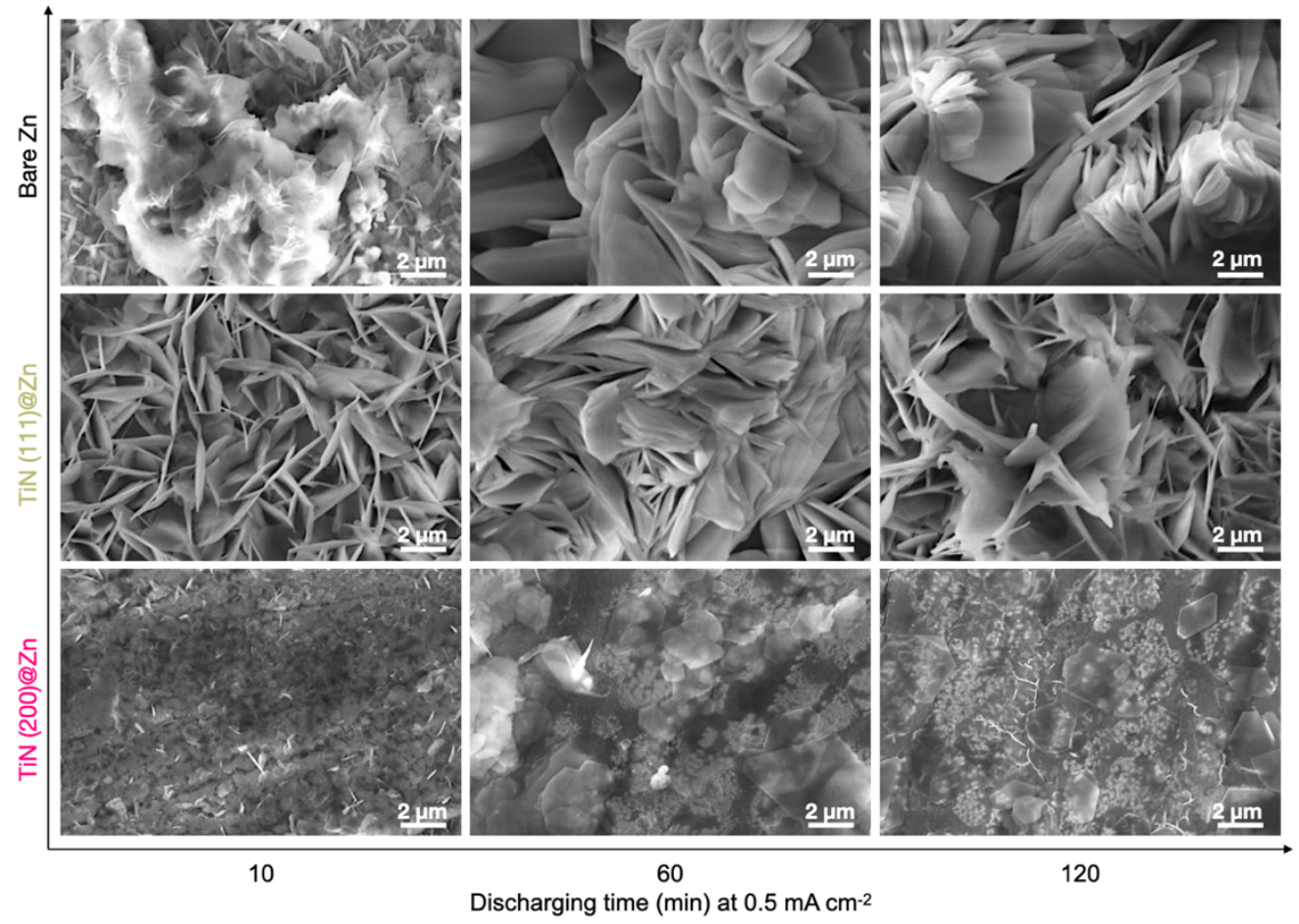

Figure S16. The morphological evolution of ZHS on the three electrodes upon discharging at $0.5 \mathrm{~mA} \mathrm{~cm}^{-2}$.
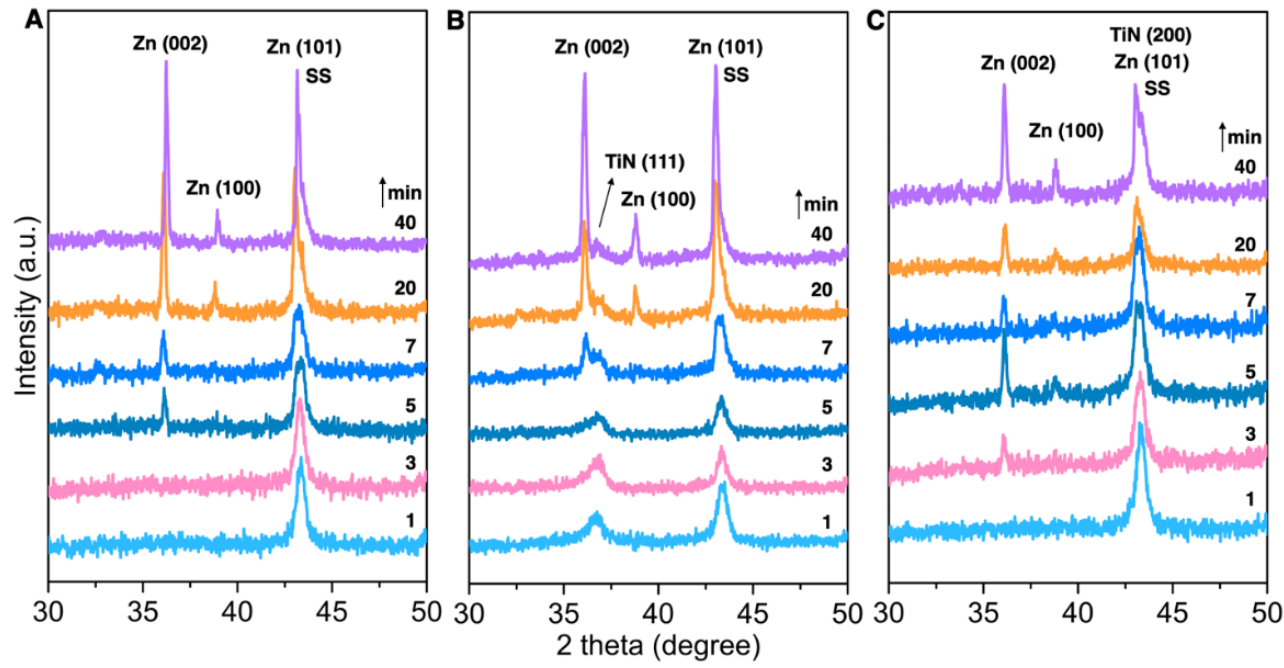

Figure S17. Time-dependent XRD patterns of the Zn deposited on (A) stainless steel foil, (B) TiN(111)@stainless steel, and (C)TiN(200)@stainless steel at 0.5 mA cm². 


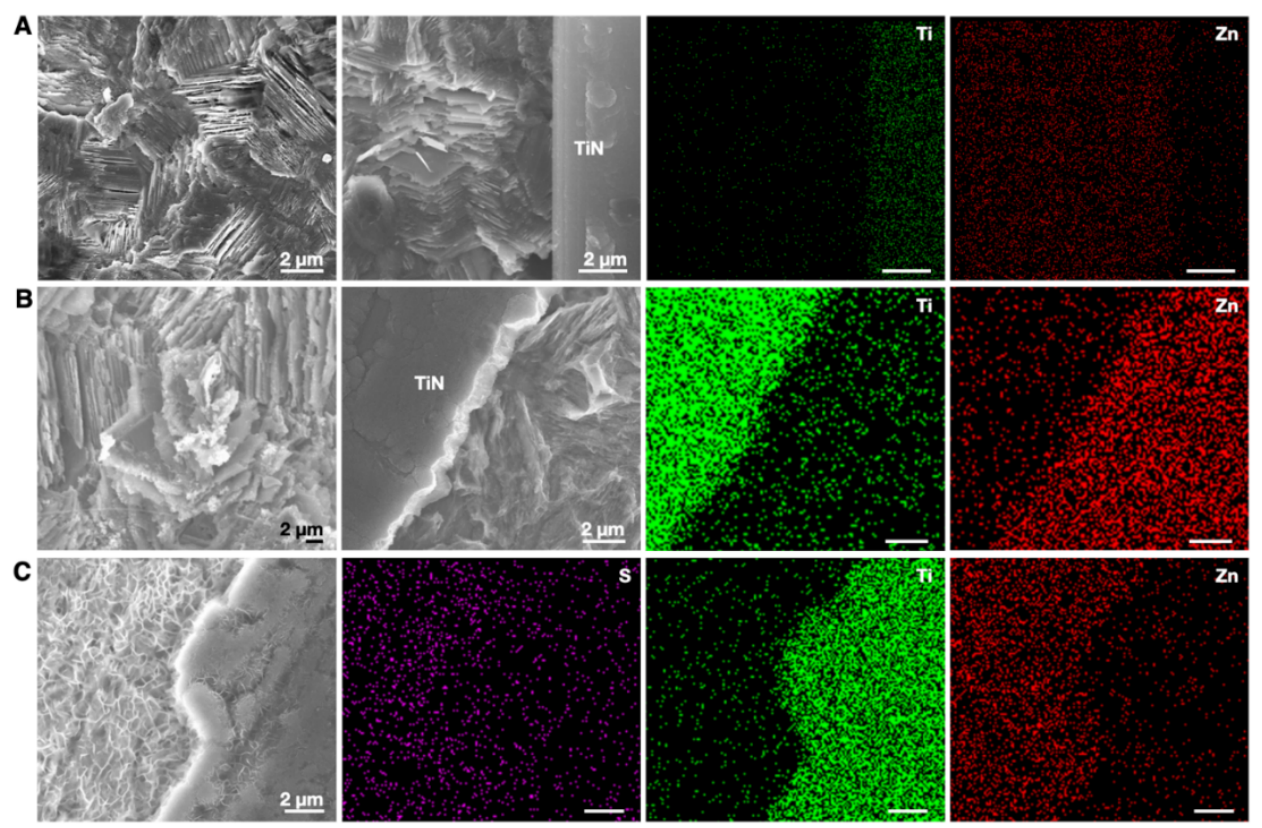

Figure S18. SEM images and elemental maps of the cycled (A) TiN (200)@Zn and (B and C) TiN (111)@Zn anodes. Because of the much higher conductivity of the Zn foil as well as the columnar structure of TiN coatings, the $\mathrm{Zn}^{2+}$ ions could travel through vertical channels among the TiN columns, and deposit onto the underneath Zn foil. In S15A and B, the TiN coatings were intentionally peeled off by ultrasonic treatments with high power so that the morphology of the deposited $\mathrm{Zn}$ can be seen, which is distinctly different from that of ZHS (S15C). It is worth mentioning that we didn't observe detectable S signals from the elemental mapping, indicating that ZHS only forms at the surface of TiN coatings. 

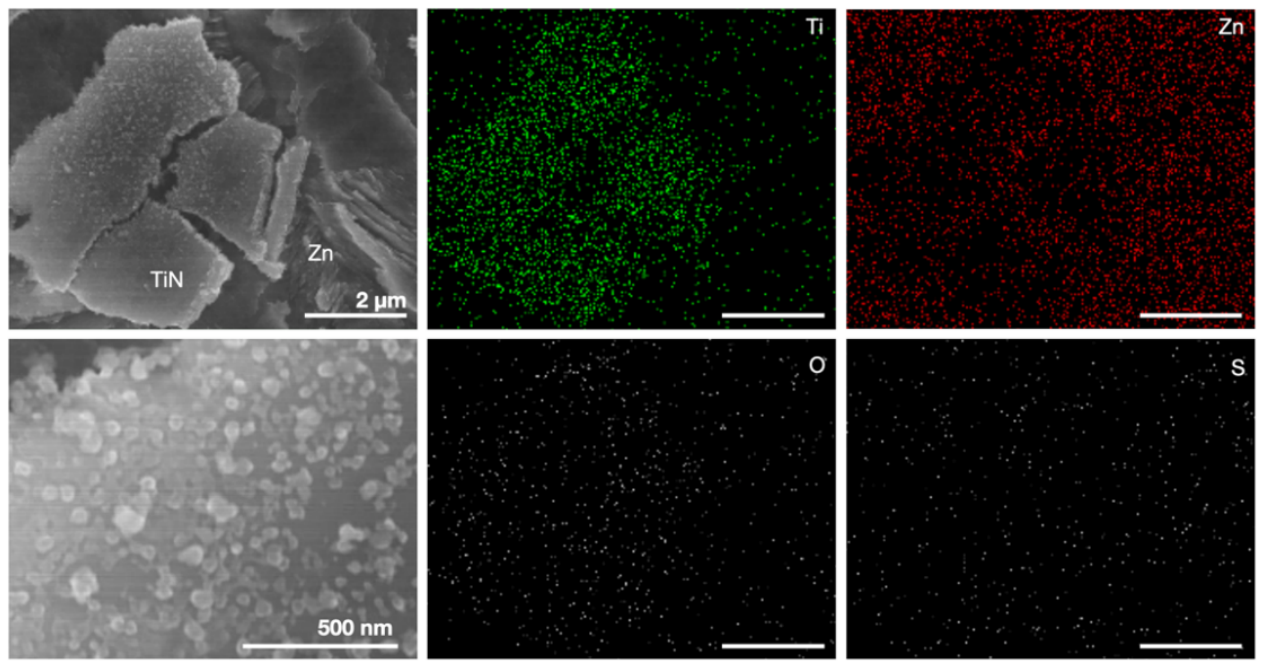

Figure S19. SEM images and elemental maps of the cycled TiN (200)@Zn after etching. Cycling conditions: $0.5 \mathrm{~mA} \mathrm{~cm}{ }^{-2}, 4 \mathrm{~h}$. The elemental mapping reveals that there is barely $\mathrm{S}$ left.

\section{Electrochemical performance of full cells}
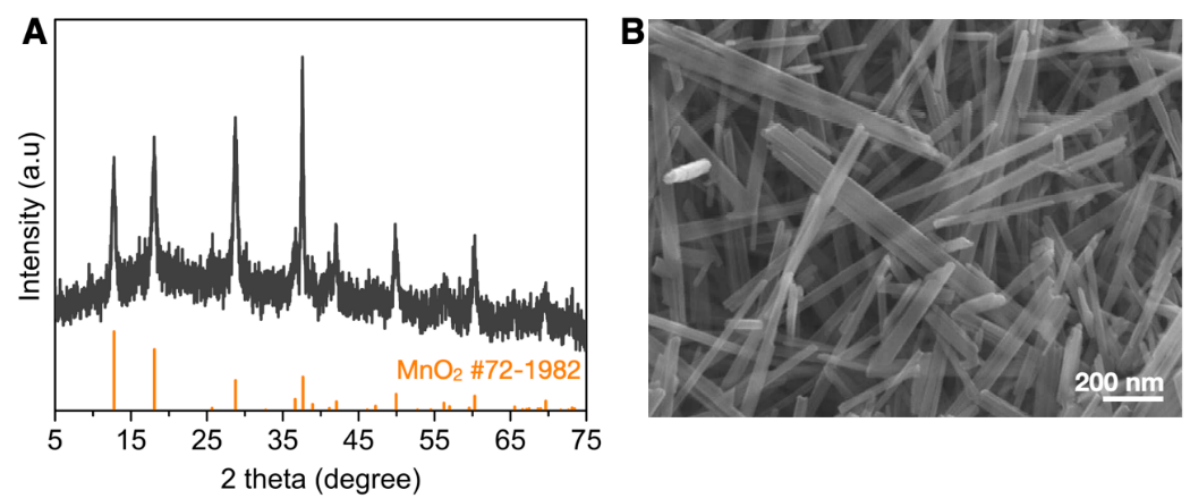

Figure S20. (A) XRD pattern and (B) SEM image of the $\mathrm{MnO}_{2}$ nanowires.

We have shown that the specific TiN facets could suppress the side reaction and regulate the growth pattern of ZHS nanosheets and therefore enhance the electrochemical performance. We further evaluated its potential in full cells using $\mathrm{MnO}_{2}$ nanowires (Figure S20) as the cathode. We used the solution of $2 \mathrm{M} \mathrm{ZnSO}_{4}$ and $0.1 \mathrm{M} \mathrm{MnSO}_{4}$ as the electrolyte as it has been demonstrated that the addition of $\mathrm{MnSO}_{4}$ in the electrolyte can suppress the dissolution of $\mathrm{MnO}_{2}$ cathode and therefore enhance the stability. ${ }^{5}$ 

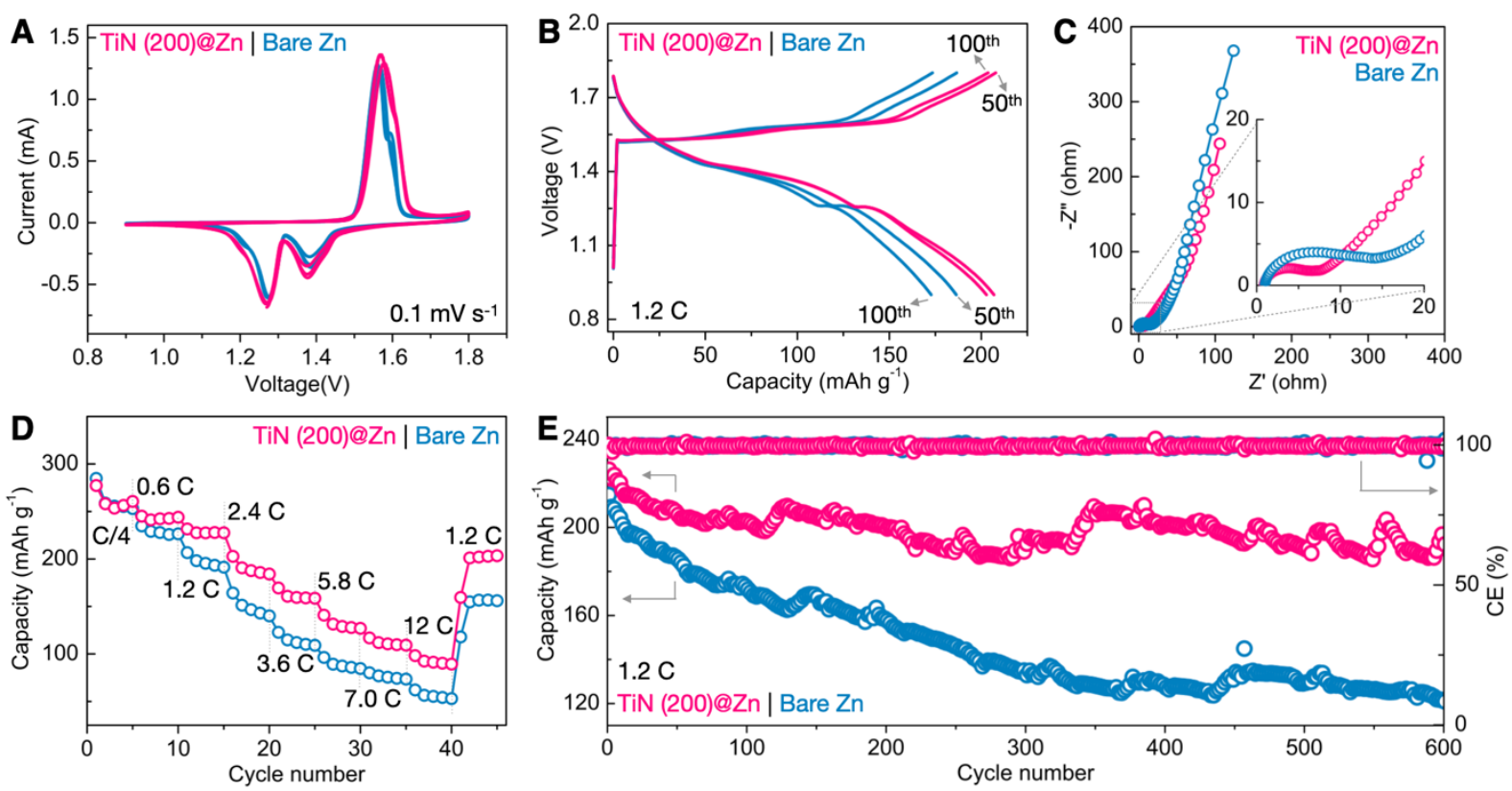

Figure S21. Electrochemical performance of TiN (200)@ $\mathrm{Zn} \mid \mathrm{Mn} \mathrm{O}_{2}$ full cells. A) CV curves at $\left.0.1 \mathrm{mV} \mathrm{s}^{-1}, \mathrm{~B}\right) \mathrm{CD}$ profiles at $1.2 \mathrm{C}$ rate, C) Nyquist plots, D) rate capability at various rates, and E) cycling stability at $1.2 \mathrm{C}$ rate of the TiN (200)@ $\mathrm{Zn} \mid \mathrm{MnO}_{2}$ and $\mathrm{Zn} \mid \mathrm{MnO}_{2}$ full cells (1 C $\left.=616 \mathrm{~mA} \mathrm{~g}^{-1}\right)$. Electrolyte: $2 \mathrm{M} \mathrm{ZnSO}_{4}+0.1 \mathrm{M} \mathrm{MnSO}_{4}$.

$\mathrm{MnO}_{2}$ with a theoretical capacity of $\sim 616 \mathrm{mAh} \mathrm{g}^{-1}$ (based on two electrons transfer) was used as the cathode. Figure S21A compares the cyclic voltammetry (CV) curves of the TiN (200)@ $\mathrm{Zn} \mid \mathrm{MnO}_{2}$ and bare $\mathrm{Zn} \mid \mathrm{MnO}_{2}$ cells. Both of them show two pairs of redox peaks that are associated with the oxidation/reduction of $\mathrm{Mn}(\mathrm{IV})$ to $\mathrm{Mn}(\mathrm{III}) / \mathrm{Mn}(\mathrm{II})$ species. ${ }^{6} \mathrm{In}$ addition, the two CV curves are almost identical in shape, indicating that the TiN coatings do not affect the $\mathrm{Zn}^{2+}$ intercalation chemistry. The charge-discharge (CD) profiles of both cells possess two sloping discharge plateaus at $\sim 1.4$ and $\sim 1.27 \mathrm{~V}$ (Figure S21B), corresponding to the $\mathrm{Zn}^{2+}$ insertion to $\mathrm{MnO}_{2}$ and consequently the reduction of $\mathrm{Mn}(\mathrm{IV})$ to $\mathrm{Mn}(\mathrm{III}) / \mathrm{Mn}(\mathrm{II})$, in consistent with the CV result. It is noted that upon continuous cycling, the voltage difference of the charge-discharge plateaus of TiN (200)@ $\mathrm{Zn} \mid \mathrm{MnO}_{2}$ becomes smaller than that of $\mathrm{Zn} \mid \mathrm{MnO}_{2}$ cells, yet the former delivers a higher capacity. The electrochemical impedance spectroscopy (EIS) measurements (Figure S21C) reveal that the TiN (200)@ $\mathrm{Zn} \mid \mathrm{MnO}_{2}$ cell possesses a smaller charge transfer resistance and a faster $\mathrm{Zn}^{2+}$ diffusion kinetics compared to bare $\mathrm{Zn} \mid \mathrm{MnO}_{2}$ cell, because of the unique columnar structure (Figure S3) and the high wettability of TiN coatings (Figure 1I), which therefore is expected to possess a better rate capability. Indeed, though the initial capacities of both cells are very close, the difference becomes 
bigger as the current density increases (Figure S21D). Specifically, the capacity of the TiN (200)@Zn $\mid \mathrm{MnO}_{2}$ remains $99 \mathrm{mAh} \mathrm{g}^{-1}$ at a high rate of $12 \mathrm{C}\left(1 \mathrm{C}=616 \mathrm{~mA} \mathrm{~g}^{-1}\right)$, which is $62 \%$ larger than that of the $\mathrm{Zn} \mid \mathrm{MnO}_{2}$ cell $\left(61 \mathrm{mAh} \mathrm{g}^{-1}\right)$. Furthermore, the former also exhibits a much higher stability with a capacity retention of $87 \%$ after 600 cycles at $1.2 \mathrm{C}$, whereas the latter can only deliver $57 \%$ of the initial capacity (Figure S21E). The observed periodic capacity variation might be due to the dissolution and electrodeposition of $\mathrm{MnO}_{2}$ during cycling. ${ }^{7}$ The stability test result is in agreement with that observed in symmetric cells and further confirms that the TiN (200) coatings can significantly enhance the stability of Zn ion batteries.

Table S1. Comparison of the TiN (200)@Zn and various recently reported high performance Zn anodes.

\begin{tabular}{|c|c|c|c|c|}
\hline $\mathrm{Zn}$ anode & $\begin{array}{l}\text { Current density } \\
\qquad\left(\mathrm{mA} \mathrm{cm}^{-2}\right)\end{array}$ & $\begin{array}{l}\text { Areal capacity } \\
\left(\mathrm{mAh} \mathrm{cm}^{-2}\right)\end{array}$ & $\begin{array}{c}\text { Cycling } \\
\text { lifespan (h) }\end{array}$ & Reference \\
\hline TiN & 1.0 & 1.0 & 2300 & \multirow{2}{*}{ This work } \\
\hline (200)@Zn & 2.0 & 2.0 & 1000 & \\
\hline $\mathrm{Zn}-\mathrm{Al}$ anode & 0.5 & 0.5 & 2000 & Nat. Commun. 2020, 11, 1634 \\
\hline $\mathrm{Zn} / \mathrm{IHS}$ & 1 & 0.5 & 700 & J. Am. Chem. Soc. 2021,143, 3143 \\
\hline $\mathrm{TiO}_{2} @ \mathrm{Zn}$ & 1 & 1 & $\sim 450$ & Nat. Commun. 2020, 11, 3961 \\
\hline $\mathrm{ZnO} @ \mathrm{Zn}$ & 5 & 1.25 & $\sim 500$ & Energy Environ. Sci. 2020,13,503 \\
\hline MXene@Zn & 0.2 & 0.2 & $\sim 800$ & Angew. Chem. Int. Ed. 2021, 60, 2861 \\
\hline $\mathrm{ZnF}_{2} @ \mathrm{Zn}$ & 1 & 1 & $\sim 800$ & Adv. Mater. 2021, 2007388. \\
\hline
\end{tabular}

\section{References}

1. Deng, C.; Xie, X.; Han, J.; Tang, Y.; Gao, J.; Liu, C.; Shi, X.; Zhou, J.; Liang, S., Adv. Funct. Mater. 2020, 30, 2000599.

2. Perdew, J. P.; Burke, K.; Ernzerhof, M. J. Phys. Rev. Lett. 1996, 77, 3865.

3. Jain, A.; Hautier, G.; Ong, S. P.; Moore, C. J.; Fischer, C. C.; Persson, K. A.; Ceder, G. J. Phys. Rev. B 2011, 84, 045115.

4. Wang, L.; Maxisch, T.; Ceder, G. J. Phys. Rev. B 2006, 73, 195107.

5. Yang, J.; Cao, J.; Peng, Y.; Yang, W.; Barg, S.; Liu, Z.; Kinloch, I. A.; Bissett, M. A.; Dryfe, R. A. ChemSusChem 2020, 13, 4103. 
6. Alfaruqi, M. H.; Mathew, V.; Gim, J.; Kim, S.; Song, J.; Baboo, J. P.; Choi, S. H.; Kim, J. Chem. Mater. 2015, 27, 3609-3620.

7. Kang, L.; Cui, M.; Jiang, F.; Gao, Y.; Luo, H.; Liu, J.; Liang, W.; Zhi, C. Adv. Energy Mater. 2018, 8, 1801090. 